\title{
O AMÁLGAMA COMPONENTE DOS DESTINOS TURÍSTICOS COMO CONSTRUÇÃO VIABILIZADORA DESSA PRÁTICA SÓCIO-ESPACIAL
}

\author{
Ireleno Benevides*
}

\section{RESUMO:}

O "turismo" como prática sócio-espacial tem sua compreensão amputada pela análise econômica, pela qual é considerado como atividade / setor econômico. Sua dimensão plural e qualitativa nos leva a aderir à noção de "amálgama da destinação", cujos componentes não são só recursos/insumos econômicos quantificáveis. Esta prática se viabializa pela integração de diversas atividades econômicas soldadas numa delimitada referência espacial (lugar turístico), as quais, contudo, não atendem só a demanda de turistas. À redução inscrita no conceito produção do espaço do turismo nos contrapomos com a noção metafórica de metonímia estruturante. Preocupados em singularizar a contribuição da Geografia recuperando criticamente a sua síntese clássica (o humano e o fisiográfico), imputamos a significação do valor ativo, presente, dos territórios herdados ao longo do processo de turistificação, para ressaltar o peso das restrições locacionais, fisiográficas mesmo, na seletiva espacialização do "turismo", apesar de considerar que este seja fruto de uma invenção sócio-cultural.

\section{PALAVRAS-CHAVE:}

amálgama da destinação; prática sócio-espacial; turistificação; metonímia estruturante; territórios herdados / projetados.

\section{ABSTRACT:}

The " tourism " as social-spcial practice has its understanding amputated by the economic analysis, which is considered as activity / economic section. Its plural and qualitative dimension takes us to assimilate the notion of " amalgam of the destination ", whose components are not just quantifield economic resources / input. This practice makes possible itself by the integration of several economic activities welded on a defined spacial reference (tourist place) whose, however, don't only assist the tourists' demand. To the reduction registered in the concept production of the space of the tourism we oppose ourselves with the metaphoric notion of structured metonymy. Worried in making single the contribution of the Geography recovering them critically its classic synthesis (the human and the physiographic), we imput the significance of the active value, present, of the territories inherited along the touristification process, to stand out the weight of the rent restrictions, even physiographic, in the selective spacialization of the "tourism ", in spite of considering it is a result of a social-cultural invention.

\section{KEY WORDS:}

amalgam of the destination; social-spacial practice; touristification; strutured metonymy; inherited / porjected territories. 


\section{Introdução}

Compreender o turismo como uma série de práticas sócio-espaciais, que impulsionam diversas atividades econômicas, amalgamadas numa delimitada base territorial, parte da perspectiva de que considerá-lo como atividade econômica carece de uma elementar manifestação, pois esta suposta atividade não tem uma evidência empírica específica. ${ }^{1}$ Essa consideração privilegia a categoria consumo turístico de um lugar. Neste encontram-se atrativos, suportes, infra-estruturas, para que turistas potenciais efetivem suas viagens circunstanciadas pelo tempo do não-trabalho e pelo espaço da não-moradia habitual, o que lhes permite fruição de temporalidades e espacialidades extraordinárias, extra ordem diária. Por conseguinte, novas formas de sociabilidade aí aparecem, condicionando a que o lazer, o lúdico, o entretenimento e o prazer demarquem a interação fulgaz entre os visitantes das destinações turísticas. Aí estão amalgamados os componentes de "atrações, de amenidades - hospedagem, venda de comidas e bebidas, entretenimento, comércio varejista e outros serviços - de acesso - transporte local terminal de transporte - e de serviços auxiliares na forma de empresas e organizações locais" (SHEPHERD, 2001, 136-137).

É em função prioritária deste consumo que se (re)organiza um território adequado para práticas turísticas acontecerem. Excluindo-se os resorts, compreendidos como enclaves, territórios de confinamento, nas demais situações, principalmente relativas aos centros urbanos, aquelas atividades econômicas não são exclusivamente destinadas a suprir a demanda de seus visitantes.

O componente do deslocamento espacial como requisito para o consumo turístico acontecer leva, contudo, a que ele não se restrinja à sua objetividade material, posto que ele está principalmente involucrado por sugestões do desfrute do "prazer imaginário" (URRY, 1996) extraordinariamente possível nos "espacios de ócio" (NICOLAS, 1996), daí a relevância de seus aspectos simbólicos ${ }^{2}$. Esta não-restrição diz respeito também ao entorno em que determinados objetos turísticos de absoluta singularidade e visitação estão localizados, e que, por isso, fundem-se com aquela simbologia, como, por exemplo, o Pãode-Açúcar, não só por conta da sua fisiografia de seu entorno, elementarmente monumental.

Da dimensão espacial expressa na fixidez da oferta de produtos e serviços turísticos (SANCHEZ, 1991; URRY, 1996; BERTONCELLO, 1998) decorre também essas sugestões, proporcionadas pelas associações entre o produto/serviço ofertado e o lugar que o prove - o seu entorno geográfico - bem como das práticas que o envolvem. Isso faz com que o deslocar-se tenha também uma "caráter existencial e psicanalítico" (FERRARA, 1996). O lugar turístico não é só o resultado da objetividade material produzida, mas também de representações aí imaginadas que abrigam e referenciam fantasias e projeções.

Os aspectos simbólicos de que as práticas turísticas se revestem, bem como esse caráter espacial dos deslocamentos nelas inscritos, conseqüentemente, acarretam problemas de precisão e de aferição afeitos a "um campo de pesquisa dominado pela visão econômica... [e] por interesses econômicos que concorrem para ver neste fenômeno somente sua face mercante pela empresa turística" (KNAFOU, 1996, 69).

\section{Para além da análise econômica convencional: turismo não é atividade / setor produtivo}

Embora a construção de territórios específicos voltados para abrigar práticas turísticas decorra de uma série de atividades produtivas e ações políticas que conferem concretude, objetividade e quantificação a essa construção, a produção e o consumo desses territórios requerem uma compreensão que extrapola variáveis para aferi-las pelo recorte da análise econômica convencional.

Um recorte inscrito na complexa noção de oferta turística expresso em um longo enunciado 
O amálgama componente dos destinos turísticos como

construção viabilizadora dessa prática sócio-espacial, pp. 85 - 101

de LEMOS, inclui, contudo, variáveis indicadoras do consumo elementar do espaço, tais como fatores climáticos, que não podem ainda receber uma aferição e contrapartida monetárias, inscritas no mecanismo de preços relativos. Portanto, nessa complexa exposição enumerativa dos elementos componentes da oferta turística já ficam indicados os amplos aspectos da produção de uma ambiência, estrutura e suporte, que extrapolam delimitações designadoras e aferidoras da produção econômica de bens e de serviços usuais.

Por este enunciado,

"pode-se definir a produção turística como a combinação dos fatores que irão gerar determinada quantidade de bens e serviços turísticos. $O(s)$ produto(s) é (são) portanto o conjunto de bens e serviços que envolvem a informação do turista acerca do local a ser visitado, seu deslocamento, sua estadia naquela localidade, as mercadorias por ele adquiridas, os locais de visitação, os fatores socioculturais, climáticos e geográficos e os elementos das infraestruturas geral e específica a eles ofertados e por eles consumidos nas localidades-destino" (LEMOS, 2000, 95).

Embora de forma elementar, esse enunciado já aponta para os dois sentidos da categoria produção. Em seu sentido restrito, expressa a dimensão econômica. Contudo, referências a fatores sócio-culturais, climáticos e "geográficos" evidenciam o amplo sentido de produção, por nós interpretado como a criação de uma complexa ambiência, que leve em conta, portanto, a dimensão não econômica do processo de turistificação dos lugares e as condições de sua manutenção no tempo.

Do que foi considerado anteriormente, é lícito admitir da impossibilidade de classificação compartimentalizada, baseada na singularidade produtiva, concreta e diferenciada do que seja a atividade turística, distinta de outra atividade econômica. Isso decorre da especificidade de que turismo não é uma atividade econômica em si, mas uma prática sócio-espacial que articula diversas atividades, que não têm, contudo, os turistas como seus consumidores exclusivos ${ }^{3}$. Sua singularidade é, portanto, uma manifestação daquilo que aparece na realidade empírica de forma plural, como um conjunto de produtos e serviços ofertados pelos três setores componentes da economia, referenciados por um território, que abriga diferentes possibilidades desta prática.

Face à tipologia ideal de prática turística, existem, na realidade, situações que diferem de uma simplificação conceitual, abstrata. ${ }^{4}$ Tomemos, então, para efeitos de compreensão uma situação que comumente seria identificada como própria a essa prática, pois diria respeito a um tipo de uso que é habitualmente monopolizado pelos viajantes.

Vem se tornando freqüente o fato de organizações hoteleiras incentivarem, com preços e promoções, o consumo desse equipamento pela população local, principalmente nos fins de semana, em cidades com grandes fluxos de turismo de negócios, ou nos períodos de baixa estação do turismo de "ócio". Numa aferição estatística que pesquisasse estas organizações, como unidade de coleta de dados, estes casos contribuiriam para superdimensionar os fluxos turísticos. Contudo, se nesses casos os deslocamentos espaciais são minimalistas, o mesmo pode não ocorrer com o caráter existencial e psicanalítico que esse deslocamento simbólico pode promover. Esses deslocamentos teriam, contudo, uma grande contrapartida existencial e motivadora do lazer extraordinário, da fuga da quotidianeidade doméstica habitual.

Por outro lado, existem turistas que viajam em transporte próprio e hospedam-se em casa de amigos e parentes ${ }^{5}$, compartilhando aí predominantemente de práticas de lazer "ordinário" 6 ou consumindo elementarmente espaço, diante do que podem ser muito bem considerados como desocupados locais ou flaneurs, desfrutando do seu ócio em territórios urbanos. Contudo, estas mesmas práticas não deixam de ter a significação de invólucros extraordinários para estes turistas. 
Tais situações constituem evidências de que aferições do fenômeno do turismo, restritas às suas manifestações apreendidas por indicadores econômicos, embora "...indispensáveis, não resumem uma reflexão sobre o fenômeno e a natureza ainda mal conhecida do que seja turismo." (KNAFOU, 1996, 69).

As amputações que decorrem, por um lado, de reduzir as práticas turísticas ã suas expressões econômicas e, por outro lado, os próprios atributos extra-econômicos contidos no extenso conceito de LEMOS (2000) nos levam à noção de turistificação, compreendida como processo de criação de uma ampla ambiência apropriada7 às práticas turísticas para, com isso, abranger os contextos objetivos e as representações subjetivas que motivam deslocamentos espaciais e existenciais.

Por essa ambiência entenda-se não somente, em termos econômicos, a sua reconfiguração material, expressa na valorização turística de muitos atributos locais transformados em atrativos pela agregação de trabalho a eles, mas também o modo como essa ambiência recebe outra valoração, traduzida nas atitudes que compõem a singularidade da sociabilidade turística e impele aqueles deslocamentos.

\section{As práticas turísticas: metonímias estruturantes da produção material e simbólica de um território multifuncional}

Em sua acepção geral e abrangente, práticas sociais compreendem conjunto de ações motivadas para a consecução de objetivos e de interesses grupais. Por esse conjunto queremos afirmar que estes objetivos conferem sentido e orientação coletivos, ao promover identidades entre aqueles que delas participam. Ao constituírem referências para a interação destes praticantes, esses objetivos orientam comportamentos assemelhados, baseados em três características dessas práticas.

Elas se afirmam pela aceitação de alguns padrões comuns, através dos quais um grupo se orienta por normas, procedimentos e valores compartilhados. Esse compartilhamento, como segunda característica, significa que essas práticas são internalizadas na conduta geral dos indivíduos, estabelecendo entre eles mais elementos de sintonia do que de conflito, em virtude da adesão e da comunhão de significados. Esses significados referem-se ao fato de que as práticas sociais se revestem de elementos simbólicos, que, através de uma representação social específica, porém comumente partilhada no tempo e no espaço, norteiam a integração e a identificação entre os seus praticantes.

Esse terceiro elemento, enfatizado para as práticas turísticas, no que se refere à variação de significados no tempo e no espaço dos produtos e dos seus lugares receptores destas práticas, decorre da consideração elementar de que o que é atrativo para alguns pode não o ser para outros. Há, portanto, diferentes e dinâmicas modelações que conferem significação, para que referências e produções materiais e simbólicas de um espaço se convertam em atrativos turísticos, segundo a alteração do gosto em épocas diferentes, ou por gostos diferentemente compartilhados pelas classes sociais numa mesma época. Torna-se aqui oportuno ressaltar que nem sempre os preços são as variáveis fundamentais para recortar inicialmente esses significados.

As produções sócio-econômicas e culturais existentes em um lugar não têm uma genérica e imanente valoração turística, posto que são contingencialmente (re)elaboradas por modelos históricos e estéticos. Há, portanto, uma certa datação e estratificação nesses modelos, ou seja, são temporal e socialmente valorados por suas aptidões, moldadas "... ao ritmo de publicidade, de modas culturais e esportivas, de critérios estéticos e de possibilidades técnicas e estratégias de mercado" (SILVEIRA, 1997, 37).

A refuncionalização do espaço pelas práticas turísticas, que decorrem desses modelos, significa produzir no espaço anterior, herdado, condições objetivas para sua valorização turística, já levando em conta, 
O amálgama componente dos destinos turísticos como

construção viabilizadora dessa prática sócio-espacial, pp. 85 - 101

contudo, muitas vezes essas aptidões herdadas (o valor do espaço), referenciadas pelos quadros de uma cultura, como condicionantes para a sua conservação valorizada. Isso nos remete à noção de apropriação, como posse e como readequação dessas aptidões ${ }^{8}$, que se tornam compatíveis para o consumo turístico, em função de um trabalho material ou imaterial que incide sobre este espaço herdado, ou mesmo de uma mera nova representação.

pois

Por práticas espaciais compreendemos

"um conjunto de práticas através das quais são criadas, mantidas, desfeitas e refeitas as formas e as interações espaciais... [ou seja] um conjunto de ações espacialmente localizadas que impactam diretamente sobre o espaço" (CORREA, 1995, 35).

Podemos então inferir que estas práticas decorrem da percepção e da consciência dos sujeitos sociais sobre como os recursos estão seletivamente valorados, distribuídos no espaço, passíveis de receberem diferentes modos de valorização, por diversos projetos configuradores de um específico arranjo territorial. Por isso, o mesmo autor citado salienta que elas

"são meios objetivos através dos quais objetivase a gestão do território, isto é a administração e o controle da organização espacial em sua existência e reprodução" (ibidem).

A compreensão do turismo como prática sócio-espacial não é aqui considerada somente pelo consumo dos territórios turísticos. Diz respeito também aos sujeitos envolvidos nas "três fontes de turistificação dos lugares e dos espaços" (KNAFOU, 1996), ou seja, a práticas voltadas para produzir o espaço do turismo. Dentre essas fontes, este autor cita aquela decorrente de originários citadinos em suas vilegiaturas. Nestes casos, não são produtos que estão na origem deste processo, mas sim suas práticas considerando também que, como hipótese, esta fonte não está totalmente seca.

Porto Seguro, na Bahia, e Canoa
Quebrada e Jericoacoara, no Ceará, exemplificam essa fonte, que predominou na turistificação inicial da Terra da Luz, diante da qual, de um certo modo, busca contrapor-se a concepção do PRODETUR-CE, calcado nas ações de "planejadores e promotores territoriais". Resta saber, então, se, face à atual lógica predominante de produção de territórios turísticos, envolvendo "grandes grupos monopolistas e administração" (LIPIETZ, 1989), que promovem a ocupação planejada desses territórios, quais espaços e rincões ainda restariam para a remanescência daquela fonte?

Em turismo, as categorias consumo e produção não se restringem à sua dimensão econômica convencional, que, por ela vista, compreende diversos ramos e atividades produtivas conformados para atender, preferencialmente, à demanda dos turistas, orientada por significativas pregnância e referência territorializadas dessas atividades. Essa conformação suscita uma preocupação sistêmica, que se volta também para o meio ambiente e a paisagem num lugar turístico, no sentido de não comprometer a atratividade deste lugar. Há portanto razões objetivas, funcionalmente econômicas, para preocupações ambientais no turismo, tendo em vista que "atributos naturais do espaço exercem importante papel na eleição de determinadas porções de território pelo turismo" (CRUZ, 1990, 113), bem como na sustentação a longo prazo da atratividade. Assim, a preservação ambiental vista por uma ótica tradicional como não produção econômica na verdade é uma estratégia de "produção imaterial", não transformadora.

O sentido dessas preocupações evidencia-se, por exemplo, pela seguinte consideração. No caso de uma indústria, essa pode "muito bem" conviver com formas de gestão, mantenedoras de altos níveis de emissão de poluentes, configurados como "externalidades" que afetam a qualidade ambiental, mas não necessariamente a de seus produtos e de seus lucros. Em outra situação, a taxa de ocupação de um hotel pode ficar 
comprometida em função das transformações de seu entorno, que alterem sua ambiência agradável, o que configura, em parte, casos de hotéis que foram sendo fechados fechando no centro de Fortaleza.

A dimensão espacial dos deslocamentos, por seu turno, se reflete na dimensão social, no sentido de que esses deslocamentos são em grande parte realizados em grupo, onde a sociabilidade turística constitui o vetor significativo para o estabelecimento das formas de compartilhamento, de interação. Inobstante, mesmo quando viajam sozinhos, os indivíduos levam consigo, internalizados em suas condutas, padrões e significados socialmente apreendidos e partilhados, através dos quais interagem com outros viajantes nos lugares de turismo receptivo.

Esses deslocamentos têm também o seu conteúdo existencial no sentido de que apartando-se dos lugares de residência e do trabalho - a atratividade dos lugares turísticos é também induzida cultural e midiaticamente pelos signos associados ao inusitado, ao prazer, ao lazer, ao consumo cultural, ao descanso à liberdade, à "saída do armário". Portanto, o caráter "extraordinário" das práticas turísticas é conferido pelas vivências conformadas por uma outra temporalidade atribuída, que envolve objetos e lugares que tornam possíveis estas vivências acontecerem concomitantemente a outras. Por isso, o mesmo trajeto feito nas "balsas" do Rio de Janeiro para Niterói pelo mar da baía de Guanabara, ou até mesmo uma visita à praia do Futuro, em Fortaleza, têm, ambos, representações diferentes para os turistas e para os moradores locais. São diferentes as formas de apropriação e de fruição simbólicas do trajeto e da praia, evidenciando, com isso, também, que o consumo humano não é só satisfação material, mas também realização de fantasias, involucradas de subjetivismos.

Talvez por isso é que, nas observações do senso comum, não seja difícil distinguir turistas de residentes, misturados nesses locais. Por isso é que a dimensão existencial do deslocamento, do desenraizamento, significa também possibilidades de ruptura com "aquilo que nos é habitual" (URRY, 1996), igualmente inscrito na ordem, produtivista, burocrática e familiar (MARCUSE, 1979) e, como tal, muitas vezes repressora de subjetividades "diferentes" dessa ordem predominante ${ }^{9}$. O turista não é um outro estranho a nós, mas um outro de nós, que carregamos, muitas vezes desejosos e sombreados no mundo predominantemente opaco do cotidiano organizado pelo trabalho, que tantas vezes queremos negá-lo, apartando-se dele, para tornar luminosos e realizáveis desejos e sonhos de "liberdade"10, desatando os nós que nos prendem à referida engrenagem do "homem unidimensional" (ibidem).

Os fatores promotores dos deslocamentos assim se cruzam na consideração de que o componente existencial, subjetivo, não está dissociado do espacial (fisiográfico), objetivo, expresso na busca de experienciar também outras territorialidades proporcionadas preferencialmente por lugares da permanência fugaz, do não-trabalho. Daí que são as práticas turísticas que constituem a referência significativa para arranjos territoriais em suas dimensões material e simbólica existirem.

No geral, dividindo seu uso com outras práticas e funções, os territórios são denominados de turísticos pelo fato de eles se (re)modelarem, orientados significativamente para abrigar práticas turísticas, que são relevantes, porém, não exclusivas para sua organização. Isso significa que é em torno de atividades econômicas e de infra-estruturas, ambas viabilizadoras do consumo turístico, que se estabelecem consensos, intervenções, planos, programas e mesmo delimitação de sua área geográfica. Nessa perspectiva capital imobiliário, ações públicas de desenvolvimento urbanístico e empreendimentos turísticos podem se amalgamar em grandes coalisões para a valorização do espaço.

Considerando que as grandes cidades abrigam a maioria dos fluxos turísticos mundiais, e que estas são conformadas por múltiplas funções, compreendemos a produção do espaço para o turism o com o um ametonímia estruturante, 
O amálgama componente dos destinos turísticos como

construção viabilizadora dessa prática sócio-espacial, pp. 85 - 101

decorrente do peso e da influência que a função turística tem na produção do espaço, bem como no curso e no sentido da expansão urbana. Por outro lado, nas situações que se projetam em espaços com pouco ou nenhum nível de urbanização, o consumo turístico representa a possibilidade prioritária para (re)valorizar e (re)aproveitar uma gama de atributos e recursos locais.

Essa metonímia torna-se também reluzente, devido tanto ao caráter mais visível sedutor, amplo e midiático ${ }^{11}$ que as imagens turísticas provocam, bem como à natureza indicativa do uso prioritário de uma dada fração do espaço, conforme consubstanciado no conteúdo dos instrumentos de gestão do território ${ }^{12}$. Isso se traduz no fato de que os inventários, enquanto verdadeiros diagnósticos territoriais, e os sistemas de informações têm, nas chamadas potencialidades turísticas, a referência prioritária de seus conteúdos temáticos, bem como a logística de circulação implantada tem, em um território turístico projetado, os eixos de sua estruturação.

Desse modo, inventários territoriais, sistemas de informações e logística de circulação constituem três instrumentos apropriáveis pelo planejamento do turismo, ou seja, instrumentos destinados a territórios projetados à imagem e semelhança das práticas turísticas. A isso agreguem-se normas técnicas e critérios disciplinadores e orientadores idealmente regulando e fornecendo parâmetros para usos presentes e futuros. Enfim, tudo se volta para priorizar a consolidação de práticas turísticas, como preponderantes da refuncionalização desses territórios.

O estruturante advém da consideração de que as práticas turísticas têm papel predominante na configuração das quadrículas do poder (RAFFESTIN, 1993). A metonímia reporta-se ao argumento de que, como parte relevante dessa configuração, a qualificação desses territórios, suscitada pelas práticas turísticas, é tomada como parcela designadora da sua totalidade. Isto compreende, na dimensão da ação estatal, o processo pelo qual se fundamentam os conteúdos dos instrumentos do planejamento e da gestão sobre os territórios. $\mathrm{Na}$ teia que se vai urdindo para e na (re)construção ${ }^{13}$ desses territórios, o papel estruturante é exercido pela extensão, pela relevância e pela intensidade que as atividades e serviços de lazer turístico e os suportes infraestruturais a ele ligados têm na lógica que projeta e orienta a produção de seus fluxos e de seus fixos.

Por conseguinte, um território como fração funcional do espaço (SANTOS, 1996), como espaço geográfico concreto num dado momento, com limites estabelecidos (SANCHEZ, 1991), é qualificado como turístico pelo fato de que objetos turísticos e objetos infra-estruturais de acesso e de suporte ${ }^{14}$ são relevantes para determinar seus principais fluxos e para esquadrinhar os pontos delineadores de seus limites. Em síntese, há relevância das práticas turísticas na modelagem desses territórios, principalmente no que se refere à ação do Estado. Essa relevância pode ser compreendido a pelo cotejo de duas situações brevemente comparadas nos dois parágrafos seguintes.

A cidade de São Paulo, em relação à região referenciada pela praia do Cumbuco, situada a oeste de Fortaleza, em sua Região Metropolitana, tem um número incomparavelmente mais significativo de equipamentos turísticos, a despeito de estes não terem, como têm nesta localidade, papel expressivo no seu ordenamento territorial. Isso porque a ampla multifuncionalidade daquela megalópole leva a que as práticas turísticas aí convivam num espaço tecido por uma teia de complexas relações.

A outra situação, referente à Porto Seguro, mostra como a turistificação muitas vezes assume a função de hipertrofiar atividades voltadas para o consumo de seus visitantes. Isto pode refletir-se negativamente no atendimento de demandas locais, exemplificada aí pela ausência de salas de cinema, que, todavia, do ponto de vista do turismo de lazer, sol e praia, é secundária para o tipo de entretenimento demandado. O próprio horário de funcionamento 
de uma série de atividades ligadas ao comércio e aos serviços obedece a temporalidades afeitas a um sistema de turnos de trabalho condicionados pelo regime de fruição do tempo dos turistas, diferente do que é usual para os moradores desta cidade.

Esses singulares exemplos podem, contudo, adquirir relevância, ao imputar-lhe um valor significativo das formas de como vêm se desenvolvendo a turistificação, principalmente no Nordeste, - descurando-se de outras demandas e temporalidades locais - tanto pelas práticas turísticas espontâneas como pelos promotores e planejadores territoriais, devido às conexões seletivas e impositivas que esse tipo de turismo estabelece com o local.

\section{O valor ativo dos territórios herdados no processo de turistificação no Ceará}

Embora o conceito de turistificação tenha pertinência e significação gerais para designar a relevância das práticas turísticas na (re)funcionalização de um território, no Ceará, especificamente, as formas de turistificação ganham outras abrangências e repercussões, tornando-se alvo também de tácitas políticas de marketing governamental destinadas a produzir imagens exitosas de administrações públicas. Daí que a unidade espacial que referencia este segmento é o território cearense, sobre o qual nos concentraremos em apresentar - embora passível de um reducionismo esquemático - duas formas básicas de turistificação.

Uma forma de turistificação volta-se para o (re)aproveitamento de inúmero recursos/ atributos (produtivos ${ }^{15}$, arquitetônicos, culturais, ambientais, culinários, fisiográficos e paisagísticos) existentes num lugar, passíveis de serem inventariados para posterior apropriação, como atrativos e produtos destinados preferencialmente ao consumo turístico. Agregue-se a tudo isso a produção de uma imagem turística síntese, objetivando demarcar, semiótica e mercadologicamente, sua singularidade no mercado e no imaginário turísticos. Essa forma, referente à (re)criação desta ampla ambiência para posterior implantação de objetos turísticos, desdobra-se em duas situações demarcadas por diferentes níveis de urbanização de um lugar.

Uma situação ocorre em territórios que, mesmo com algum estágio prévio de urbanização, ainda preservam, em seu entorno urbano imediato, recursos ambientais, paisagísticos e fisiográficos, aptos ao desfrute e à vivência turísticos, em que "a natureza" ainda é grande atrativo. A isso correspondem localidades portadoras de pequeno desenvolvimento econômico, portanto, com maiores possibilidades de persistência de atividades produtivas tradicionais, o que tende a se refletir em contingências favoráveis para preservar porções desta "primeira natureza". Isso permite resguardar uma geografia urbana idealizada como típica representante de temporalidades pretéritas, em que bucolismo e urbanidade pareciam conviver, o que é exemplarmente cabível na pequena cidade de Pacatuba e no seu entorno imediato, que integram a Região Metropolitana de Fortaleza.

Essas possibilidades de turistificação projetam-se pela capacidade de transformar algumas localidades em atração turística consoante com a ampliação para as regiões tropicais da tendência de "busca da periferia"16 por práticas turísticas Algumas dessas situações compreendem municípios não litorâneos cearenses contemplados por Planos de Ação Turística ${ }^{17}$, muitos ainda em lentíssima execução.

Outra situação, que ocorre em espaços praticamente não urbanizados, portanto carecendo de mínimos suportes necessários ao desenvolvimento de práticas turísticas, ${ }^{18}$ requer previamente infra-estrutura, pois "urbaniza-se, prevendo (e desejando-se) o uso turístico futuro" (CRUZ, 2000, 12). Como variante daquilo que LUCHIARI denominou de urbanização turística para o caso de Ubatuba, (1999), onde turismo e urbanidade se retroalimentam sincronicamente, essa situação corresponde ao que CRUZ chamou de urbanização para o turismo, para o qual requerse "uma política urbana que faz às vezes de uma política de turismo" (2000, 142). Daí suas 
O amálgama componente dos destinos turísticos como

construção viabilizadora dessa prática sócio-espacial, pp. 85 - 101

implicações no discurso de promoção social que - PRODETUR (Programa de Ação para o Desenvolvimento do Turismo na Região Nordeste) faz para as localidades por ele contempladas.

Quando uma complexa urbanização precede à turistificação, esta ambiência caracteriza-se pela proliferação de objetos turísticos em construção, facilitada pelos objetossuporte já instalados. Isso não impede que os desdobramentos decorrentes da intensificação do processo de turistificação nestas cidades não vão influir na direção e na feição do seu desenvolvimento urbanístico, bem como no uso predominante de novos objetos-suporte. Neste caso, as práticas turísticas passam a comandar a modernização técnica e a estetização da sua paisagem, característica de urbanização para fins turísticos. Essa situação fica mais explícita no papel das metrópoles no processo de turistificação de muitos espaços regionais, por concentrarem o maior fluxo de turistas, inclusive ordenando-os e irradiando-os para sua periferia.

A segunda forma de turistificação refere-se ao privilegiamento de expressões ambientais, fisiográficas e paisagísticas, em virtude de sua relativa "intocabilidade", o que é mais cabível ao processo histórico que comandou a ocupação de porções do litoral cearense. O conhecimento dessas expressões e principalmente sua sistematização foram possíveis por uma amplo inventário territorial promovido pelo PRODETURIS (Programa de Desenvolvimento do Turismo do Litoral do Ceará), que gerou informações sobre potencialidades estratégicas. Ao mapear o litoral cearense, produziu, conseqüentemente, uma 'cartografia turística exploratória, para subsidiar a ação dos planejadores e promotores territoriais, passível de orientar a construção de uma infraestrutura suporte e de implantar uma nova logística de circulação no território, que projetam fluxos turísticos.

Nas duas situações, o elemento comum é o fato de que é comum é que o processo de turistificação compreende o modo pelo qual as práticas turísticas exercem função significativa e às vezes preponderante ${ }^{19}$ na tessitura das várias relações produtoras de um território. Isso se dá pela (re)utilização de diferentes recursos/ atributos e produções locais, materiais e imateriais já existentes, bem como pela construção de novos símbolos e objetos, voltados preferencialmente para a promoção e consumo turísticos.

Quando esta relevância assume a dimensão de verdadeiro amálgama aglutinador, portanto, produtor de uma destinação, as práticas turísticas exercem o papel estruturante, constituindo o vetor de uma transversalidade operativa das interfaces entre o econômico, o comportamental, o cultural, o recreativo, o paisagístico e o fisiográfico. Assim seleciona nessas esferas o que é relevante e apropriável para a refuncionalização dos territórios onde esses elementos se encontram, na medida em que podem se converter em recursos turísticos. E, portanto, a possibilidade de práticas turísticas que orienta significativamente a nova funcionalização de manifestações já existentes nas várias esferas da chamada totalidade social, articulando e integrando essas manifestações em um plano de ação.

O papel que as práticas turísticas podem assumir na promoção daquelas interfaces nos leva a aderir a imputação de John Urry sobre o caráter prefigurativamente pós-moderno do turismo. Referenciado por LASH (1990), URRY ressalta as relações do turismo com as manifestações pós-modernas ${ }^{20}$, camaleonicamente circunscritas a um novo "regime de significação, cujo traço estruturante fundamental é a desdiferenciação" (1996). Muitas práticas turísticas contemporâneas constituem evidências dessa desdiferenciação, ao articular num lugar, combinatória e funcionalmente, várias expressões das referidas esferas, daí a generalização do princípio banalizado de que tudo pode-se transformar em objeto do consumo e de prática turísticas. Ao apropriar-se destas expressões, impingindo-Ihes novas possibilidades, esse consumo tende a dissolver, entre outras coisas, as fronteiras entre "produção artística e aquilo que é comercial", entre o estético e o social, entre o cultural e o 
entretenimento, amalgamando-os na configuração de espetáculo e pastiche, portanto imprimindo-Ihes um caráter anti-aurático e antiromântico" (Idem, ibidem.).

É com base nessas referências que o amálgama estabelecido para a abrigar práticas turísticas é por nós interpretado como uma espécie de síntese cultural21, pois articula variadas possibilidades de (re)utilização daqueles recursos e produção locais. Essa suma, ao efetivar tais possibilidades, esses recursos e produções herdados são elevados à condição de atrativos capazes de sustentar e de diversificar as práticas turísticas em um delimitado arranjo territorial ${ }^{22}$.

A remodelação de recursos e produções existentes num território turistificável decorre tanto de transformações simbólicas, ou seja, atribuição de outras significações (valoração), bem como de uma valorização ${ }^{23}$ desses recursos e produções, entendida como realização do valor, responsáveis por uma outra material configuração do território ao que lhe conferir novas significações e funções. Aquelas ações de remodelação não apenas incidem sobre o território, como suporte, mas o modificam, em conteúdo e forma, expressando assim a indissociabilidade entre sistemas de objetos e sistemas de ações, que o definem num dado momento e processualmente o redefinem (SANTOS, 1994, 111).

A apropriação turística resulta de práticas espaciais que orientam a refuncionalização de recursos, produções e imagens de um lugar e de suas paisagens para o consumo turístico, bem como de atitudes que só se tornam turísticas em um lugar, referenciado pelas especificidades e representações de seus objetos de sua sociabilidade e de seus símbolos.

A referência à fixidez espacial desse consumo, ou seja, à liturgias e ritos que associam o ato de consumir ao deslocamento para um outro lugar, corresponde ao seu complementar econômico, referente à fixidez espacial da oferta turística. Isto corresponde à consideração de que práticas e atividades turísticas só ganham o seu sentido mentado, sua verdadeira vazão, por vivências associadas a territorialidades não simbolizadas pelo mundo do trabalho e da residência habitual. ${ }^{24}$

Por isso, essa fixidez não remete apenas ao componente material do consumo, expresso nas singularidades dos objetos pretensamente ofertados num lugar turístico, mas a uma certa fixação em não dissociar o consumo de um lugar específico, pois só aí ele é imaginariamente possível, posto que é este lugar que reveste este consumo de alguma "aura" irremovível. Daí a irredutível associação entre os atos de consumir e de viajar. Exemplificando-se, não é somente o ato de hospedar-se num hotel com padrões de excelência na qualidade de seus serviços que preside a escolha de um destino, podendo, em alguns casos, essa qualidade ser secundária em si, como também secundarizada, face a uma simbologia e a um valor imaterialmente agregados, como possibilidade de vivências extraordinárias, ou seja, como lugar de algum sonho, de alguma fantasia 25 .

Desse modo, o consumo turístico está involucrado, circunstanciado por referências, adstritas a um lugar. Se do ponto de vista material aquela oferta tem fixidez, do ponto de vista simbólico a demanda está referenciada também por aspectos projetivos que fixam o consumo às imagens que alguns lugares ofertados "exclusiva e extraordinariamente " provocam. ${ }^{26}$

\section{As restrições locacionais herdadas na seletividade espacial das práticas turísticas}

As práticas turísticas denotam exemplificações, especificidades, que podem ser alçadas à condição de evidências para proporcionar uma reflexão sobre a natureza do espaço, sobre o qual, neste segmento apenas apresentamos breves considerações.

O entendimento de que o espaço não é somente suporte, mas que ele também conta, que ele tem, como espaço herdado e anteriormente construído, valor ativo na configuração do presente, nos remete à questão 
O amálgama componente dos destinos turísticos como

construção viabilizadora dessa prática sócio-espacial, pp. 85 - 101

do caráter autônomo - porém não independente do saber geral - da Geografia. Esse caráter reside na possibilidade dessa disciplina fornecer uma contribuição particular, irredutível, para a construção de uma teoria social, ao apresentar consistência, adequação e pertinência próprias, indispensáveis e legítimas no tratamento do espaço, enquanto ente analítico específico. Isso remete à um recorte particular do real, do qual esse ente é seu objeto, compreendido a partir de sua histórica construção humana, material e simbólica, objeto teórico, sobre o qual a Geografia exerce sua contribuição epistemológica. ${ }^{27}$

Por uma perspectiva geral, esse entendimento é basilar para a construção de uma Geografia pautada na análise da natureza do espaço. Por uma perspectiva particular, atinente à abordagem do turismo, por mais que esta confira à atratividade turística e aos seus territórios a condição de invenção cultural, restrições locacionais herdadas influem na determinação da oferta turística, pois um território, embora

"repleto de política e de ideologia... não pode estar completamente separado dos espaços físicos e psicológicos... [pois] a vida social nunca está inteiramente livre de choques restritivos" (SOJA, 1993, 148).

Dessas restrições decorre a seletividade espacial, que diz respeito ao modo como os homens atuam diferenciadamente no processo de apropriação e de organização do espaço ao turismo, pelo fato de atributos, julgados atrativos, ${ }^{28}$ não se distribuírem uniformemente por toda a superfície terrestre, ${ }^{29}$ ou seja, estarem seletivamente localizados em partes desta. Entretanto, a marca desta natureza herdada, que em alguns casos pode ser primeira "... não é ingênua e independentemente dada, ...pois seu impacto social sempre passa por uma segunda natureza que emerge da aplicação organizada e cumulativa do trabalho e do conhecimento humanos" (SOJA, 1993, 148), prenhe de representações.
$\mathrm{Na}$ tessitura dessas considerações, para delimitar o valor ativo dos territórios ${ }^{30}$ herdados e neles projetar uma turistificação, três referências de autores, com relevantes contribuições para a fundamentação científica da geografia humana e da abordagem geográfica do turismo evidenciam a parcela que ainda cabe a fatores fisiográficos e a sua combinação singular na produção do espaço em geral e do turismo em particular. Considerando a pertinência desses argumentos, achamos que algumas reproduções textuais são suficientes por si mesmas. Ei-las:

«... avanzaremos en el papel de las caracteristicas de los elementos fisicos del espacio para ver cualles pueden ser utilizados y cualles modificados. Es dicir, para descubrir como cada espaço, em si mismo, possibilita uno u otro tipo de funcionalizacion... Quando nos dirigimos a un espacio físico lo hacemos en funcion de la presencia de una combinacion de caracteristicas, que lo hagan adecuado para su uso... En nuestro caso, no toda combinacion sol/clima, agua/mar y playa/costa, es suficiente para configurar un espacio que sirva a una utilizacion turística.» (SANCHEZ, 1991, 220-21).

"Aliás, as feições naturais do território ... têm, ainda hoje, influência sobre a maneira como se dá a divisão do trabalho. Formas naturais e formas artificiais são virtualidades, a utilizar ou não, mas cuja presença no processo de trabalho é importante." (SANTOS, 1996, 112) ${ }^{31}$.

El turismo como atividad humana es la unica que aprovecha el espacio tanto por su valor paisagistico, como por las condiciones ambientales que prevalecen (clima, hidrologia, vegetacion, etc) (NICOLAS, 1989, 57)

Deste modo, o componente da fixidez daqueles referidos recursos valorados e de sua combinação singular num dado território, condicionando conseqüentemente a fixidez da oferta turística, remete à questão das restrições locacionais, ou seja, da distribuição espacialmente desigual de atributos variavelmente valorizados para as práticas turísticas, que vai influir nas seletividades de um lugar turistificável. 


\section{Considerações finais: a reiteração das diferenças}

Embora o turismo seja uma invenção sócio-cultural, simbólica e materialmente valorizada pela ação do homem num dado território, o que por isso mesmo faz com que esta prática não dependa de uma inerente valoração com base em fatores fisiográficos ou antropicamente herdados, conforme as ideologias, das vocações naturais para o turismo -, não se pode desconsiderar estes fatores, como integrantes do "amálgama de componentes de uma destinação" (SHEPHERD, 2001, 137), ou seja, atributos condicionadores e produtivos de um lugar turístico. Além de uma desigual distribuição espacial de atributos, os mesmos são desigualmente valorizados em função de uma valoração mediada por culturas, épocas, gerações, classes sociais e estilos de vida.

Por outro lado, diferentes mediações, que inclusive respondem por diferentes padrões de organização do turismo, podem, contudo, ter como alvo uma mesma motivação (por exemplo, o turismo sol e praia massivamente realizado em Fortaleza ou comutariamente vivido na Prainha do Canto Verde, situada a $120 \mathrm{~km}$ ao leste de Fortaleza). Diferentes possibilidades técnicas, que se articulam intencionalmente para uma valorização turística, produzem e promovem diferentes amálgamas, sem que com isto se estabeleça um juízo de valor maniqueísta sobre o "bom" e o "mau" turismo.

1 A concepção de turismo como um conjunto de práticas sociais que articulam atividades econômicas referenciadas às especificidades de um lugar é indicada em CARLOS (1996, 112), para quem "o setor turístico compõe-se de uma multiplicidade de atividades referentes à produção concreta de um lugar."

2 Considerando a hierarquia das necessidades humanas, segundo a clássica exposição da A.H. Maslow, o consumo turístico teria posição secundária ou até mesmo supérflua, caso se tenha
Compreender as práticas turísticas como um amálgama aglutinador de diferentes componentes que se soldam de modo diferente num lugar transformado em destino turístico, como síntese combinatória de recursos e de expressões das várias esferas integrantes da chamada totalidade social num dado contexto histórico-geográfico, requer também que não se estabeleça uma estanque contraposição entre invenção sócio-cultural e atributos historicamente herdados e fisiograficamente concentrados ${ }^{32}$. Ambos concorrem para um processo de turistificação, como os inventários turísticos bem exemplificam, ao classificar regiões com diferentes potencialidades turísticas.

Este amálgama compreende a (re)apropriação combinada, funcional, de recursos, de produções materiais e de referências simbólicas ${ }^{33}$ que estão potencialmente em condições de ativar as práticas turísticas, sintonizadas com o contexto motivacional da demanda ${ }^{34}$ e reportadas a um lugar como destino turístico. Tal amálgama se reproduz internamente por outra seletividade, através da qual são elegidas no território herdado algumas expressões referentes às várias esferas da totalidade "local" (economia, cultura, ${ }^{35}$ arquitetura, ambiente, paisagem e etc), em função das suas aptidões projetadas para vivências turísticas em torno um novo arranjo territorial que vai se moldando.

em mente a estrutura de distribuição da renda e da riqueza mundiais, disponíveis ainda a uma pequena parcela da sua população. Pois bem, é justamente na produção de necessidades supérfluas, embora socialmente necessárias, posto que significativas na produção de padrões contemporâneos de consumo, compatíveis com os requisitos da sociedade de massas, que simulacros e simbologias são mais urdidos pelas estratégicas mercadológicas.

3 Considerando as referências da economia contemporânea, capitalista, os vários mercados setoriais de bens e serviços compreendem o 
O amálgama componente dos destinos turísticos como

construção viabilizadora dessa prática sócio-espacial, pp. 85 - 101

encontro - mediado pelas atividades comerciais - de ofertantes (empresas produtoras) e demandantes (os consumidores), caracterizados a partir do bem/serviço que possibilite esse efêmera sociabilidade mercantil, expressa nas ações de compra e venda. Daí as várias designações: escolas e alunos (economia da educação), hospitais e enfermos (economia da saúde), livros e leitores (mercado editorial), etc. Nessa perspectiva, o turista não é propriamente um consumidor específico de um produto, mas um sujeito social que articula várias práticas de consumo com deslocamentos espaciais temporários.

4 Essa conotação de ideal e essa simplificação conceitual são aqui tomadas com base na contribuição metodológica de WEBER (1977).

5 Isso não parece ser o caso da produção de estatísticas pela Secretaria de Turismo do Estado do Ceará, que teve acuidade de mostrar que de 1999 a 2001 em torno de 50\% de turistas de Fortaleza se situam neste caso, nas quais estão certamente incluídos os "turistas de raiz" (TELES, 2002). Isso condiciona que a tradicional hospitalidade cearense seja relevante como componente de promoção do turismo, o que, contudo, não significa que ela se adeqüe ao conceito de hospitalidade turística profissionalizada (DIAS, 2002).

6 Essa adjetivo aspeado é empregado para realçar o seu sentido em contraposição do extraordinário, para denotá-lo como ligado ao turismo. Nesse sentido, não guarda a significação com o que ele assume no senso comum, como vulgar, medíocre. Foi, portanto, tomado de empréstimo a URRY, segundo o qual "o turismo resulta da divisão binária entre ordinário / cotidiano e extraordinário" $(1996,28)$

7 A ambivalência do termo "apropriada" é aqui intencionalmente empregada para conotar tanto seu significado econômico de tornar esses atributos como propriedade para as práticas turísticas, bem como no sentido de metamorfose simbólica, como ajustável as essas mesmas práticas.

8 As metamorfoses nas representações da praia ao longo do imaginário ocidental na modernidade e sua invenção como lugar de um novo espetáculo social, expresso na vilegiatura marítima, são evidências das contingências históricas desses modelos, conforme CORBIN (1989) apresenta em seu estudo já clássico.
9 Os chamados turismo "single" (MORAES, 2001), as relações entre viagens e sexualidade não somente atado à estereotipação do prostiturismo (BENEVIDES, 2002) e o turismo GLS (ANGEL, 2001 e OLIVEIRA, 2002) inserem-se nessas possibilidades de ruptura com "enraizamentos forçados".

10 Uma postura de incômodo, que as vezes subrepticiamente, noutras nem tanto, perpassando artigos de "críticas" primárias ao turismo hegemônico, pode revelar mais elementos para uma análise psicológica de quem os produz do que propriamente geográfica dos seus conteúdos. BAUMAN sugere que os turistas têm aptidão para a "liberdade, autonomia ou independência" e que a "peculiaridade da vida turística é estar em movimento" (1998, 114), o que é, de um certo modo, corroborado por KNAFOU, que argumenta que "o turista incomoda, sobretudo por ser estrangeiro e móvel: nossa sociedade, que sob diversas formas participa de uma crescente mobilidade, nem sempre aceita muito bem o que se mexe: é difícil de se controlar o que se movimenta e, além do que, é fugidio. Há, aqui, invisivelmente ou em germinação, a recusa do Outro" (1996, 64).

11 Esses adjetivos foram aqui empregados para denotar out-doors estrategicamente colocados em pontos da Marginal-Pinheiros e da Avenida Paulista, em São Paulo, "mostrando" o turismo cearense

12 Estes instrumentos referem-se a conceitos extraídos em notas de aula da disciplina Geografia Política, ministrado pelo prof. dr. Wanderley Messias da Costa, no programa de pós-graduação em Geografia Humana, durante o segundo semestre de 1996. Eles foram aqui aplicados, partindo da consideração de que o Estado monopoliza a produção e a gestão do espaço em grandes dimensões.

13 A urdição para a (re)construção refere-se ao processo de planejamento, como antecipação espacial, que CORREA (1995) designa como manifestação de outra prática espacial, que diz respeito ao processo de conceber-se infraestruturas, ou seja, ao estabelecimento dos sistemas de engenharia no território.

14 Compreendemos por objetos turísticos uma série de equipamentos que são significativamente consumidos pelos turistas, tais como hotéis, parques temáticos, barracas de praia, mirantes, museus. Objetos suporte compreendem uma série 
de equipamentos que dão a base infra-estrutural para as práticas turísticas, tais como marinas, aeroportos, ancoradouros, estações ferroviárias ou rodoviárias

15 A nomeação de produtivo, no sentido de valor de uso, para diferenciar de econômico, denotando atividade mercantil, refere-se a atividades que subsistem nesses lugares, mas se encontram ameaçadas de extinção, em virtude da competitividade causada por empresas que operam em maiores escalas econômica e geográfica, invadindo estes nichos remanescentes, tais como doces, cosméticos e licores caseiros. Se essas produções tendem a desvalorizar-se, num mercado mais amplamente integrado, por mecanismo de preços e de logística, elas podem, por outro, ser revalorizadas para constituir mercadorias com destinação turística, o que vale dizer passando de antigas formas dominantes de prover o consumo local para o novo consumo turístico, como forma de souvenir e de "exotismo".

16 "O turismo é atraído para a periferia das áreas de ocupação humana de lugares centrais e concentrações industriais, na medida em que busca locais nas montanhas mais altas, nos bosques mais solitários e nas praias mais afastadas, onde se pode ter recreação e esporte mais facilmente que em outras partes. Christaller caracterizou essa busca de locais afastados na periferia por um processo de incorporação de áreas periféricas às localidades exploradas pelo comércio turístico" (EUFRÁSIO, 1996, 292).

17 Esses planos compreendem tentativas de articular as propostas de municipalização do turismo e "a ideologia do desenvolvimento local, ligada ao desejo político de evitar formas mais visíveis de abandono do território" (KNAFOU, 1996, 71) com os projetos de constituição de corredores turísticos a partir de um município polarizador. Essas ações podem acabar, contudo, esquecendo-se de considerar a seletividade espacial no condicionamento das práticas turísticas. De fato, em muitos casos no Ceará a idéia de municipalização do turismo foi traduzida na sua mera institucionalidade burocrática em departamentos/ secretarias, em municípios carentes das mínimas condições e pré-requisitos para seu desenvolvimento. Isso acaba por dar ressonância a outro irônico argumento de KNAFOU de que nestes casos "podese dar ao luxo de relativamente ignorar o turista assim como o mercado." (1996, 171). As ideologias do "turismo de inclusão" são manifestações dessa ignorância. (CORIOLANO, 2003).

18 Por isso não se pode desconsiderar que as práticas turísticas, enquanto respostas concretas a vários tipos de motivações integrantes do contexto motivacional da demanda turística - exigem criação de infraestrutura para viabilizá-las, pois são fenômenos circunscritos a contextos informados e conformados pela urbanização. Isso não significa dizer que as práticas turísticas só se desenvolvam em contextos urbanizados, haja vista o crescimento do ecoturismo, do turismo rural, do turismo de aventura, que se dão em ambientes rurais, mas que dependem de estruturas para viabilizá-los, que se reportam, em última instância, aos requisitos da urbanidade. Para isso, referenciando-se em MUNT (1994), SERRANO argumenta que a experiência turística "alternativa" não consegue escapar de espaços que são ordenados pela lógica da racionalidade do mercado turístico, em crescente segmentação e apropriação de novos roteiros de viagens (2000, 50-51). Dentro desse contexto, a partir de uma leitura de LABATE, é que podemos considerar que, embora as experiências contemporâneas de viagens não se reduzam ao modelo da "indústria do turismo", esta, contudo, continua sendo o paradigma dominante a orientar tais experiências. Assim, mesmo fora desse modelo, essas viagens recebem a mediação de "um conjunto de experiências codificadas" por esta indústria (2000, 56-59). Daí o caráter utópico e/ou residual da confusa, idéia de turismo comunitário e social.

19 Referenciamo-nos em AZZONI, para designar que o papel significativo seria correspondido pela noção de "desenvolvimento do turismo na região" enquanto o preponderante como "desenvolvimento turístico da região" (1993).

20 Embora tendo em mente o debate sobre pósmodernidade ou modernidade tardia - com uma vasta literatura correspondente - para discutir a natureza da sociedade e da cultura contemporâneas, essa discussão não é aqui incorporada em virtude do escopo desse artigo.

21 Síntese cultural porque "nosso presente histórico é caracterizado pela fusão entre cultura e economia" (CEVASCO, 2001, 9). No bojo dessa fusão estão articulados também turismo e entretenimento como promotores de prósperos negócios, em torno de grandes cidades. Daí que o "empresariamento" destas é demarcado pela crescente importância da valoração 
O amálgama componente dos destinos turísticos como

construção viabilizadora dessa prática sócio-espacial, pp. 85 - 101

do espaço urbano nas estratégias contemporâneas do capital, responsável pela (re) construção de muitas cidades, como cidade-mercadoria (SANCHEZ, 2003) na qual ela mesma se transforma em atração turística. Como comenta a nota seguinte, essa síntese está penetrando também cidades de porte muito pequeno, como Guaramiranga, que vai convertendo-se em pólo de significativo turismo cultural interno no Ceará, e mesmo interestadual durante o Carnaval.

22 Sucessivos eventos de música, gastronomia e teatro, que em sua quase totalidade não são municiados preponderantemente por traços culturais locais visando consolidar uma região turística em construção no Ceará (maciço de Baturité/serra de Guaramiranga) - é uma evidência dessa desdiferenciação, associada à aprazibilidade, ao bucolismo, ao clima, à paisagem, todos adquirindo uma "aura" europeizada, tão cara ao imaginário de muitas elites cearenses.

23 Utilizamos esses conceitos em itálico baseados em MORAES (1999).

24 Esse dar vazão significa que a condição para desfrute de um território através do lazer, como forma predominante, é marcada por uma temporalidade contraposta ao tempo do trabalho, como condicionadora da vivência turística. Isso porque o que torna, em última instância, turística essa vivência não são só as qualidades materiais "extraordinárias" de um território, mas atitudes e pré-disposições referentes aos consumidores desse território, bastantando lembrar que para os trabalhadores em serviços turísticos estes continuam sendo ordinários territórios do trabalho.

25 Considere-se nisso o exemplo de um grupo de proprietários de pequenas pousadas situadas em localidades litorâneas do município de Trairi (Fleixeiras e Guajiru) que promoveram pacotes de fim-desemana para "casais apaixonados" sob o signo dos "luaus de novembro", envolvendo várias sugestões para vivências românticas e procurando, concomitantemente, divulgar esse destino de turismo cearense.

26 O espaço turístico é tão relevante no imaginário dos viajantes que pode fazer com que o simples, o elementar ato de transitar por esses lugares possibilite observações extraordinárias. Seguindo essa linha, numa perspectiva contrária ao que estudos principalmente calcados na confusa ideologia do turismo local, comunitário ou de inclusão - tentam impingir ao comportamento do turista quanto a sua fugacidade e artificialidade para com tudo que experiência parece verossímil considerar que, enquanto para o citadino permanente, muitas vias urbanas são trajetos fugazes, apenas suportes dos deslocamentos em seu dia-a-dia de trabalho, para os turistas elas podem corresponder a possibilidades de exercitarem o seu olhar de flaneur, ensejando em vários pontos dos trajetos parar para enxergar muitas coisas que o habitante não vê, por conta de um olhar viciado pelo bairrismo e pela afetividade ou mesmo pela banalização, inibidores de uma perspectiva mais acurada. Por isso TUAN afirma que "... o julgamento do visitante é muitas vezes válido. Sua principal contribuição é a perspectiva nova... O visitante freqüentemente é capaz de perceber méritos e defeitos em um meio ambiente que não são mais visíveis para o residente saturado pelo seu próprio olhar" (1980, 75). Essa observação de TUAN é uma evidência de que toda observação é parcial, limitada, contudo não necessariamente falseadora.

27 A ênfase na necessidade desse entendimento, em seu conteúdo e forma expositiva, é nesse parágrafo exposta, de forma sintética, com base numa compilação de algumas passagens da Introdução em que SANTOS (1996) apresenta suas referências para uma abordagem científica da natureza do espaço.

28 Esse julgamento, conforme o próprio CORREA (1995) denota, baseia-se em juízo de valor, portanto significa uma atribuição conferida por padrões culturais considerados relevantes, conseqüentemente não referenciados por atributos naturalmente configuradores de uma imanente deferência para seu uso e valorização. Mesmo assim a valoração cultural sofre de restrições locacionais.

29 Em diferentes passagens, em diferentes momentos de sua obra, SANTOS indica esse valor ativo, por exemplo, quando afirma que "...apesar dos avanços da técnica, a história não é indiferente aos dados naturais". (1994, 93) ou quando, mesmo ressalvando que embora sejam "as condições artificialmente criadas que sobressaem [ressalta a necessidade de] não se minimizar a importância das condições naturais". (SANTOS, 1996, 198).

30 Esse valor não diz respeito somente ao espaço "natural" mas também ao construído, herdado.

31 As virtualidades naturais são consideradas também por AMATO NETO em sua análise sobre uma rede de cooperação produtiva regional, argumentando que 
"... condições naturais específicas exerceram importante papel no desenvolvimento da Solinger, uma indústria alemã de cutelaria. Ela posicionou-se aproximadamente às fontes de água, de ferro e de moldura para a fabricação de fornos" $(2000,55)$. Esses condicionantes revelam-se delimitados, pois quando essas condições acabaram-se, a empresa continuou operando com sucesso, denotando assim o predomínio - o que não significa a determinação exclusiva - do ambiente construído, ou seja não "naturalmente" herdado.

32 Esquematicamente, a invenção sócio-cultural das práticas turísticas pode recair na valorização de objetos em estado de (quase) primeira natureza (paisagens intocadas, praias e lagoas praticamente virgens), ou na revalorização de objetos e de práticas culturais já existentes (engenhocas, romarias de caráter religiosodevocional, festas populares, castelos, pontes e pirâmides).

33 Cabe, contudo, explicitar que esse processo não decorre somente de uma reapropriação simbólica e por isso mesmo a construção de novo objetos turísticos e objetos suporte é que de fato tornam plenamente turísticos esses lugares.

34 Entenda-se por esse contexto tanto os aspectos quantitativos expressos na renda e nas opções de consumo, bem como desejos, aspirações, representações e fantasias que animam profundamente essas práticas, influenciadas pela cultura de uma época.

35 As relações entre cultura e turismo têm provocado debates sobre a tendência de este acelerar a transformação daquela em componente da indústria do entretenimento, subsumida à lógica da mercadoria, portanto, estereotipando, fetichizando e muitas vezes desterritorializando as manifestações culturais, desvinculando-as do universo do trabalho e do quotidiano, com sua concomitante transferência do domínio das necessidades básicas para a esfera do supérfluo suprido pelo mercado (BEZERRA DE MENESES, 1996). Fortal (carnaval fora de época em Fortaleza) fornece indicadores desse processo.

\section{Bibliografia}

AMATO NETO, João. Redes de cooperação produtiva e clusters regionais: oportunidades para pequenas e médias empresas. São Paulo : Atlas. Fundação Vanzolini, 2000.

BAUMAN, Zygmunt . O mal-estar da pósmodernidade. Rio de Janeiro : Zahar, 1998.

BENEVIDES, Ireleno P. e GONDIM, L. M. de P. "Prostiturismo feminino em Fortaleza: um encontro de Cupido com Mercúrio? IN BENEVIDES, Ireleno P. Turismo e Prodetur: dimensões e olhares em parceria. Fortaleza : UFC/BNB, 1998.

BERTONCELLO, Rodolfo. Configuración socio-espacial de los balnearios del partido de la costa (Provincia de Buenos Aires). Argentina: Instituto de Geografia, Território, n.5, 1993, p. 1-95.

BEZERRA de Menezes, ULPIANO T. Os "usos culturais" da cultura. Contribuição para uma abordagem crítica das práticas e políticas culturais IN YAZIGI, E; CRUZ, R.C.A; CARLOS, A.F. (orgs) Turismo: espaço, paisagem e cultura. São Paulo : Hucitec, 1996.

CARLOS, Ana Fani A. O turismo e a produção do não lugar. IN YAZIGI E; CRUZ, R.C.A; CARLOS, A.F. (orgs)
Turismo: espaço, paisagem e cultura. São Paulo : Hucitec, 1996.

CEVASCO, Maria Elisa. Prefácio. IN JAMENSON, Frederic. A cultura do dinheiro: ensaios sobre a globalização. Petrópolis ; RJ : Vozes, 2001.

CORIOLANO, Luzia Neide M. T. (org.). O turismo de inclusão e o desenvolvimento local. Fortaleza : Premius, 2003

CORBIN, Alain. O território do vazio: a praia no imaginário ocidental. São Paulo : Cia das Letras, 1989.

CORREIA, Roberto Lobato. Espaço: um conceito chave em Geografia. IN CASTRO, Iná E.; GOMES, P.C. da Costa; CORREIA, Roberto L. (orgs). Geografia: conceitos e temas. Rio de Janeiro : Bertrand Brasil, 1995.

CRUZ, Rita de Cássia Ariza da. Política de turismo e território. São Paulo : Contexto, 2000.

DIAS, Célia Maria de Moraes (Org.). Hospitalidade: reflexões e perspectivas Barueri/SP : Manole, 2002.

EUFRÁSIO, Mario A. O turismo nos lugares centrais e o turismo ambiental na obra de Christaller IN 
O amálgama componente dos destinos turísticos como

construção viabilizadora dessa prática sócio-espacial, pp. 85 - 101

LEMOS, Amália Ines G. de. (orgs). Turismo: impactos sócio-ambientais. São Paulo : Hucitec, 1996.

FERRARA, Lucrécia D'Alessio. O turismo dos deslocamentos virtuais IN YAZIGI, E; CRUZ, R.C.A.; CARLOS, A.F. (orgs). Turismo: espaço, paisagem e cultural. São Paulo : Hucitec, 1996.

KNAFOU, Remy. Para uma abordagem científica do turismo. IN: RODRIGUES, Adyr (org.). Turismo e geografia: reflexões teóricas e enfoques regionais. São Paulo : Hucitec, 1996.

LABATE, Beatriz Cauibe. A experiência do viajante turista na contemporaneidade IN SERRANO, Célia; BURNS, Heloisa; LUCHIARI, Maria T. (orgs.) Olhares contemporâneos sobre o turismo. Campinas : Papirus, 2000.

LASH, S. Sociology of post modernism. London: Routledge, 1990.

LEMOS, Leandro de. Turismo: que negócio é esse?: uma análise econômica do turismo. Campinas : Papirus, 1999.

LIPIETZ, Alain. O capital e seu espaço. São Paulo : Nobel, 1888.

LUCHIARI, Maria Tereza. Urbanização turística: um novo nexo entre o lugar e o mundo. In: LIMA, Luís Cruz (org.). Da cidade ao campo: a diversidade do saber fazer turístico. Fortaleza : UECE, 1998.

MARCUSE, Herbert. A ideologia da sociedade industrial: o homem unidimensional. São Paulo : Zahar. 1979. 5 ed.

MORAES, Antônio Carlos R. Contribuições para a gestão da zona costeira do Brasil: elementos para uma geografia do litoral brasileiro. São Paulo: Hucitec, 1999.

MUNT, Ian. The other pos-modern tourism: culture, travel and new medle class. Theory, culture and society vol.II pp 101-123.

NICHOLAS, Daniel Hiernaux. Mitos y realidades del mílagro turístico: "Cancun" IN NICHOLAS, Daniel Hiernaux (comp.). Teoria e praxis del espacio turístico. México : Univ. Auton. Metropolitana, 1989.

Elementos para un analisis sociogeográfico del turismo. IN RODRIGUES Adyr (org.).
Turismo e Geografia: reflexões teóricas e enfoques regionais. São Paulo : Hucitec, 1996.

RAFFESTIN, Claude. Por uma Geografia do poder. São Paulo : Ática, 1993.

SANCHEZ, Fernanda. A reinvenção das cidades para um mercado mundial Chapecó : Argos, 2003.

SANCHEZ, Juan-Eugeni. Espacio, economia y sociedad. Madri : Siglo Vinteuno, 1991

SANTOS, Milton. A Natureza do espaço. Técnica e tempo - Razão e emoção. São Paulo : Hucitec. 1996.

As metamorfoses do espaço habitado. São Paulo : Hucitec, 1994.

SERRANO, Célia M; BRUNHS, Heloisa e LUCHIARI, Maria T. (orgs.) Viagens à natureza: turismo, cultura e ambiente. Campinas : Papirus, 1997.

SHEPHERD, Rebeca (edit.) Turismo: princípios e práticas. São Paulo, 2001.

SILVEIRA, Maria Laura. Da fetichização dos lugares à produção local do turismo. IN RODRIGUES, Adyr (org.). Turismo. Modernidade. Globalização. São Paulo : Hucitec, 1997.

TELES, João Agostinho. Turismo de raiz: um estudo de caso. Fortaleza : UECE, 2002 (dissertação de mestrado) (mimeo).

TUAN, Yu-fu. Topofilia: um estudo da percepção, atitudes e valores do meio ambiente. São Paulo/Rio de Janeiro : Difel, 1980.

URRY, John. O olhar do turista: lazer e viagens nas sociedades contemporâneas. São Paulo : Studio Nobel, 1996.

WEBER, Max. Economia e sociedade: fundamentos de sociologia compreensiva. Brasília: UNB, 1991.

Trabalho enviado em agosto de 2006

Trabalho aceito em outubro de 2006 
